\section{Identifying characteristic features of the retinal and choroidal vasculature in choroideremia using optical coherence tomography angiography}

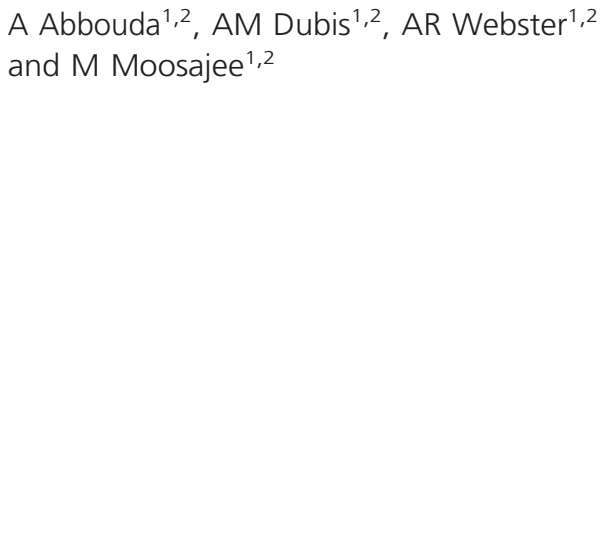

Abstract

Purpose Using optical coherence tomography angiography (OCTA) to investigate the area with flow in the superficial retinal vessel network (SVRN) and choriocapillaris (CC) layer among male subjects with choroideremia (CHM), female carriers, and normal controls to identify vascular changes.

Patients and methods Images of SRVN and CC layer were acquired in 9 affected males, 5 female carriers, and 14 age- and gendermatched controls using the Angiovue software of the RTVue XR Avanti. Results The mean age was 33 years for affected male CHM patients (median 30 years), 46 years for female carriers (median 53 years), and 39 years for controls (median 38.5). Mean SRVN area \pm SD in subjects with CHM was $12.93 \pm 2.06 \mathrm{~mm}^{2}$, in carrier subjects $15.36 \pm 0.60 \mathrm{~mm}^{2}$, and in controls $15.30 \pm 1.35 \mathrm{~mm}^{2}(P<0.01)$. The mean CC area \pm SD with flow was $6.97 \pm 5.26 \mathrm{~mm}^{2}$ in CHM subjects, $21.65 \pm 0.17 \mathrm{~mm}^{2}$ in carriers and $21.36 \pm 0.76 \mathrm{~mm}^{2}$ in controls $(P<0.01)$. SRVN and CC area with flow showed a negative correlation in CHM subjects with the age $(r=-0.86 ; P<0.003$ and $r=-0.77$; $P<0.01$, respectively). CC area with flow had a positive correlation with SRVN $(r=0.83$, $P<0.001$ ). Overall, visual acuity had a negative correlation with SRVN and CC area with flow $(r=-0.67, P<0.001$ and $r=-0.57$, $P<0.002$, respectively).

Conclusions: This is the first study to highlight changes in the SRVN in CHM subjects. OCTA detected a reduced area with flow in both retinal and choroidal circulations, and may be a useful tool for monitoring natural history and disease progression in forthcoming clinical trials. Eye (2018) 32, 563-571; doi:10.1038/eye.2017.242; published online 17 November 2017

\section{Introduction}

Choroideremia (CHM) is an X-linked chorioretinal dystrophy. It was first described in 1872 by Mauthner ${ }^{1}$ and is characterized by a progressive atrophy of the choroid, retinal pigment epithelium (RPE), and retina. The estimated prevalence is 1 in $50000-100000.2,3$ The CHM gene is located at $\mathrm{Xq} 21.2$ and encodes Rab escort protein 1 (REP1). ${ }^{2,4}$ The classical anatomical description of the choriocapillaris (CC) is a single continuous layer of capillaries forming a network on Bruch's membrane. Each segment of the CC is supplied by an independent terminal choroidal arteriole. The various segments intersect only via the venous channels. ${ }^{5}$ The lobules vary in their geometric configuration, having between three and six sides forming an irregular triangular to hexagonal shape. The average size of a lobule is between 620 and $830 \mu \mathrm{m}$ from venular to venular intersection. ${ }^{6}$ It has been proposed that the primary site of degeneration in CHM is the RPE, with a consequent loss of photoreceptors. ${ }^{7}$ This concept has been supported by the recent technology acquisition such as optical coherence tomography (OCT) ${ }^{8,9}$ However, before the advent of $\mathrm{OCT}$, the histology of $\mathrm{CHM}$ eyes showed that the primary defect presented in the uveal vessels ${ }^{10}$ with progressive choroidal thinning towards the transition zone between
${ }^{1} \mathrm{UCL}$ Institute of Ophthalmology, London, UK

${ }^{2}$ Moorfields Eye Hospital NHS Foundation Trust, London, UK

Correspondence:

M Moosajee, UCL Institute of Ophthalmology, 11-43 Bath Street, London EC1V 9EL, UK.

Tel: +44 (0)20 7608 6851; Fax: +44 (0)20 76086830 . E-mail: m.moosajee@ucl.ac. uk

Received: 10 April 2017 Accepted in revised form: 16 July 2017 Published online: 17 November 2017 
pigmented and nonpigmented fundus areas. The samples also showed extensive fragmentation of the basement membranes between the pericyte and endothelial cells, with a progressive obliteration of the CC leading to a sharply defined area of simultaneous RPE loss. ${ }^{10}$ Flannery et al ${ }^{11}$ described similar histology in a subject carrier of CHM. The CC was normal in areas with normal photoreceptors, except for widening of the intercapillary pillars. But in those regions with abnormal photoreceptors, choroidal capillaries were fewer in number, had reduced luminal diameter, and fenestrae were sparse. In some areas of intense atrophy, there were no choroidal capillaries.

The superficial retinal vessel network (SVRN) is supplied by the central retinal artery and mainly provides blood flow to the retinal nerve fiber layer and ganglion cell layer. The plexus is spread all over the retina except for three specific areas: the posterior edge of the ora serrata, the fovea avascular zone (FAZ), and the area of retina adjacent to the major arteries. ${ }^{12}$

The purpose of this paper is to identify changes in the SRVN and CC layer in vivo in affected male CHM patients and compare it with female carriers and normal subjects by optical coherence tomography angiography (OCTA).

\section{Materials and methods}

This is a prospective observational study conducted between June and October 2016 at Moorfields Eye Hospital London (UK). The protocol of this study adhered to the provisions of the Declaration of Helsinki and was approved by the national research ethics committee. Informed consent was obtained from all subjects. The inclusion criteria were a confirmed molecular diagnosis of $\mathrm{CHM}$; the exclusion criteria included the presence of any other ophthalmic disease. Affected male CHM patients, female carriers, and age-matched controls underwent OCTA imaging (Avanti RTVue XR; Optovue, Inc., Fremont, CA, USA). ${ }^{13-15}$ Macular angiograms $(6 \times 6 \mathrm{~mm})$ acquired using the Angiovue software of the RTVue XR Avanti (Optovue, Inc.) were used to detect areas of flow in otherwise static tissue ${ }^{16}$ related to the SVRN and CC flow without using fluorescein or indocyanine green dye. The FAZ was calculated at the superficial retinal layer from a macular angiogram of $3 \times 3 \mathrm{~mm}$ using the 'no flow function' provided by the same software to identify the area devoid of vessels at the centre of the macula. The SVRN was automatically segmented, using the Angiovue software (Optovue, Inc.), ${ }^{17}$ from the inner limiting membrane with an offset (from the interface reference) of $3 \mathrm{~mm}$ to the inner plexiform layer with an offset (from the interface reference) of $15 \mathrm{~mm}$, and the CC layer from the RPE with an offset (from the RPE reference) of $30 \mathrm{~mm}$ to the deeper choroidal layer with an offset (from the RPE reference) of $60 \mathrm{~mm}$. The segmentations of all examinations were checked before any measurement was performed. In subjects with CHM, the CC segmentation was performed manually ${ }^{18,19}$ for each subject to ensure proper identification of the layer reducing the risk of artefacts. In subjects with CHM, the area with CC was manually corrected by two different observers. Five measurements for each subject were collected by two observers to analyse the CC and interobserver agreement was determined using the intraclass correlation coefficient (ICC). The average of them was considered for the analysis. The 'flow' function in Angiovue was used to detect the SRVN and CC area with flow.

All statistical analyses were performed using the Statistical Package for the Social Sciences (version 21.0; SPSS Inc., an IBM Company, Chicago, IL, USA). Continuous variables are presented as the mean $\pm \mathrm{SD}$. Normal distribution of data were analysed by the Shapiro-Wilk test. Categorical variables were compared using Fisher's exact test or $\chi^{2}$ test. Parametric variables between groups were compared using the unpaired $t$-test. Levene's test was used to verify variance homogeneity. Nonparametric distributed values were analysed by the Mann-Whitney U test. For the comparison of several related samples, the ANOVA test or the Kruskal-Wallis test were used. Bivariate relationships were evaluated by Spearman's coefficient, or Pearson's analysis, as appropriate. A $P$-value of $<0.05$ was considered statistically significant. To investigate the changes with age among CHM-affected male patients, we divided patients into three subgroups according to their age $(\leqslant 30$ years, 31 to 49 years, and $\geqslant 50$ years). The mean FAZ, SRVN area, and CC area was compared between age groups using the Kruskal-Wallis test. Taking into consideration the symmetry between the right and left eye of an individual, the absence of any treatment given, and the normal distribution for many continuous variables (such as best corrected visual acuity (BCVA), refraction, FAZ, SRVN, and CC), the mean data from both eyes was considered for the statistical analysis as previously suggested. ${ }^{20,21}$

\section{Results}

A total of 17 eyes from 9 male CHM subjects and 9 eyes from 5 female carriers and 28 eyes from 14 normal subjects ( 9 men and 5 women) were included in this study. All patients and controls were Caucasian. The demographic features are summarized in Table 1. The molecular diagnosis for each subject is reported in a Supplementary Table. Mean age was 33 years (median 30 years; range 12-57 years) for affected males, 46 years (median 53 years; range 21-64 years) for carriers, and 39 years (median 38.5; range 12-60) for controls. Only one 
eye of an affected male CHM patient was excluded from the study owing to the low quality of the OCTA images and OCTA artefacts resulting from lack of fixation, and one eye of a female carrier was excluded because of previous choroidal neovascularization. Mean BCVA was $0.47 \pm 0.31 \mathrm{LogMAR}$ (median 0.17; range 0.0 to 3.0) for affected males, $-0.08 \pm 0.00$ LogMAR (median 0.0; range -0.04 to 0.0$)$ for carriers, and $-0.03 \pm 0.00 \operatorname{LogMAR}$ (median 0.0; range -0.08 to 0.03 ) for controls. The distribution of the visual acuity was statistically significant different among groups $(P<0.01)$.

Summary of SRVN, CC area with flow, and FAZ is given in Table 1. The difference in SRVN and CC between groups was statistically significant $(P<0.01$, Figures 1 a and b). However, the difference in FAZ between groups was not statistically significant $(P=0.59)$. The FAZ had a negative correlation with SRVN $(r=-0.54, P<0.003)$ and CC area with flow $(r=-0.48, P<0.008)$. Visual acuity has a negative correlation with SRVN and CC area with flow ( $r=-0.67, P<0.001$ and $r=-0.57, P<0.002$, respectively).

Analysing only affected males, the age had a positive correlation with the size of the FAZ $(r=0.75 ; P<0.01)$ and it was negatively correlated to the SRVN and CC area with flow $(r=-0.86 ; P<0.003$ and $r=-0.77 ; P<0.01$, respectively Figures $1 \mathrm{c}$ and d). Moreover, $\mathrm{CC}$ area with flow had a positive correlation with SRVN $(r=0.83$, $P<0.001)$. A high degree of reliability between the two observers measuring variables from OCTA was seen; the ICC was 0.99 with a $95 \%$ confidence interval from 0.99 to $1.0(P<0.01)$. Comparison of the mean FAZ, SRVN, and $\mathrm{CC}$ area did not show a statistically significant difference between any of the age subgroups (Table 2). However, a trend toward a progressive reduction in CC and SRVN area, and an increase in FAZ, was seen in the $\geqslant 50$-yearold group (Figure 2). Examples of SRVN and CC area with flow in each group of patients are shown in Figure 3 and Supplementary Figure 1.

In order to use the mean value between eyes, linear regression analysis was performed to determine symmetry between right and left eyes for OCTA variables. This test showed a strong degree of symmetry between eyes for FAZ $\left(r^{2}=0.74 ; P<0.01\right)$, SRVN $\left(r^{2}=0.62\right.$; $P<0.01)$, and CC area with flow $\left(r^{2}=0.98, P<0.01\right)$.

\section{Discussion}

To the best of our knowledge, this is the first paper to report the analysis of the SRVN and CC area of flow using OCTA in subjects with CHM and identify differences between affected males, female carriers, and controls. Recently, Spaide ${ }^{22}$ reported that the visualization of flow in individual choriocapillary vessels is below the current resolution limit of OCTA, but areas of absent flow signal are identified as 'flow voids'. The automatic flow function 
a

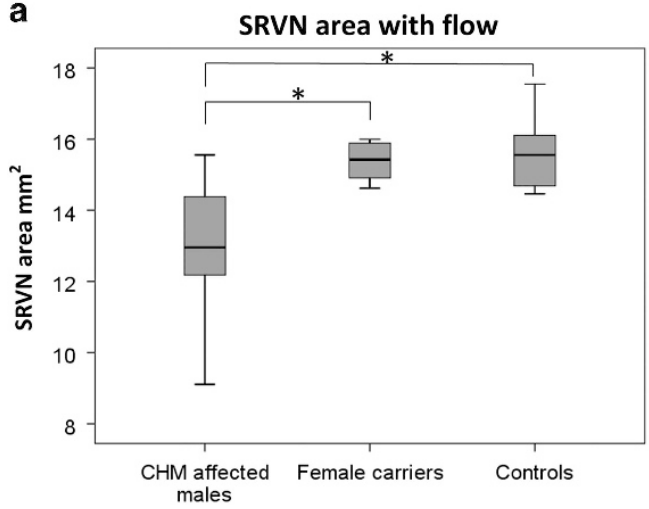

C

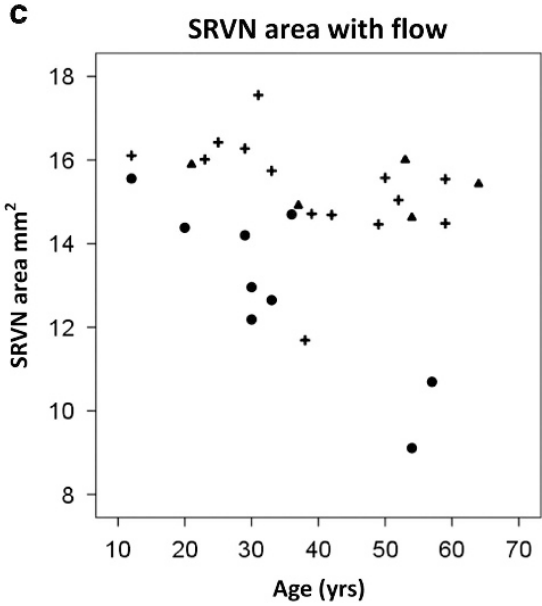

b

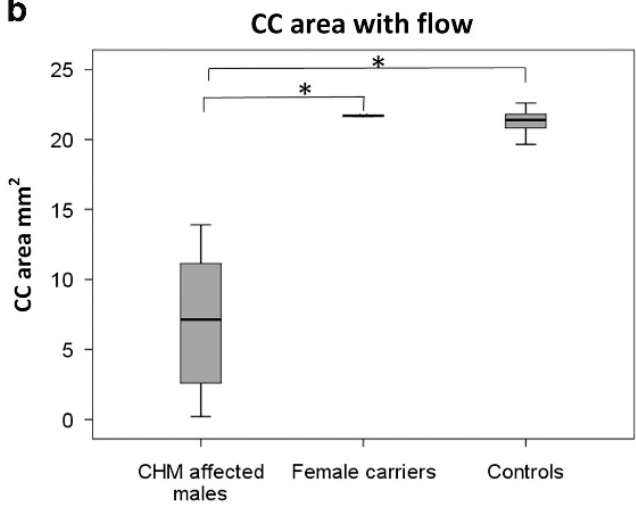

d

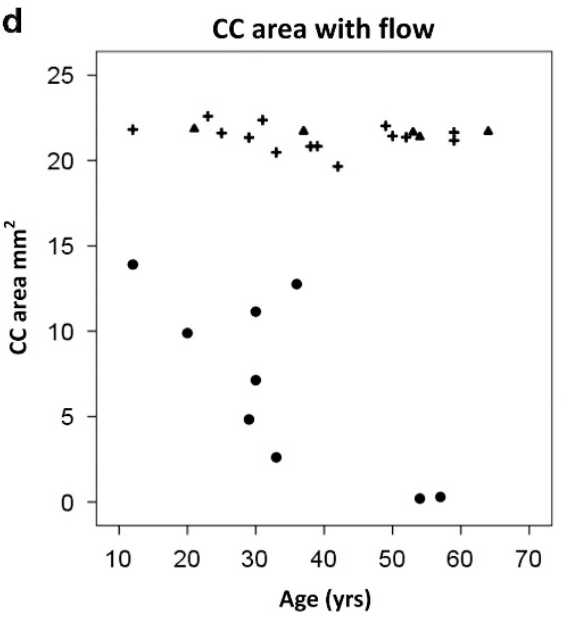

Figure 1 Boxplots illustrating the distribution of (a) superficial retinal vessel network (SRVN) and (b) choriocapillaris (CC) area with flow among $\mathrm{CHM}$ affected males, carriers, and controls. The mean ranks are represented by horizontal lines in the grey boxes. Error bars represent the minimum and maximum value. Kruskal-Wallis analysis shows statistical significant difference for SRVN $(P=0.01)$ and CC flow area $(P=0.00)$. Mann-Whitney $U$-test significance between pairs of groups are reported in the figure $\left({ }^{*} P<0.05\right)$. Scatter diagrams show relationship between age of participants and (c) SRVN area with flow and (d) CC area with flow among (o) CHM affected males, ( $\mathbf{\Lambda}$ )female carriers, and (+) controls.

Table 2 Effect of age on mean FAZ, SRVN, and CC area with flow among CHM male affected patients

\begin{tabular}{lcccc}
\hline & $\begin{array}{c}\text { Years }(\mathrm{n}=4 \text { patients, } 8 \\
\text { eyes) }\end{array}$ & $\begin{array}{c}31-49 \\
\text { Years }(\mathrm{n}=3 \text { patients, } 6 \\
\text { eyes) }\end{array}$ & $\begin{array}{c}\geqslant 50 \text { Years ( } \mathrm{n}=2 \text { patients, } 3 \\
\text { eyes) }\end{array}$ & $\begin{array}{c}\text { P-value } \\
\text { Mean } \pm \text { SD FAZ mm }\end{array}$ \\
Mean \pm SD SVRN mm & $0.20 \pm 0.71$ & $0.26 \pm 0.04$ & $1.90 \pm 1.44$ & 0.08 \\
Mean \pm SD CC area with flow mm ${ }^{2}$ & $14.27 \pm 1.06$ & $13.17 \pm 1.33$ & $9.89 \pm 1.12$ & 0.08 \\
\hline
\end{tabular}

Abbreviations: CC, choriocapillaris; FAZ, fovea avascular zone; SRVN, superficial retinal vessel network.

Values are reported as mean $\pm \mathrm{SD}$.

Kruskal-Wallis test.

provided by OCTA shows the area with perfusion based on the bright intensity of each layer providing an estimation of the area perfused. ${ }^{22}$ The instrument is not able to visualize the flow but it can furnish important information related to the normal vessel anatomical distributions. Previous papers ${ }^{23,24}$ described that the CC integrity and RPE are strictly related and the CC atrophy was correlated to RPE degeneration. A similar finding was reported by a recent paper that analysed the CC integrity in CHM subjects by OCTA. ${ }^{25}$ The authors identified the CC density was significantly lower in CHM subjects than in female carriers and controls but they did not analyse the CC area with flow. In both subjects and carriers, CC density was significantly greater underlying regions with photoreceptor preservation as opposed to regions with photoreceptor loss. ${ }^{25}$ The polarized nature of the RPE is essential for the health of the inner retina and CC. ${ }^{26,27}$ Apical and basolateral RPE secrete different 

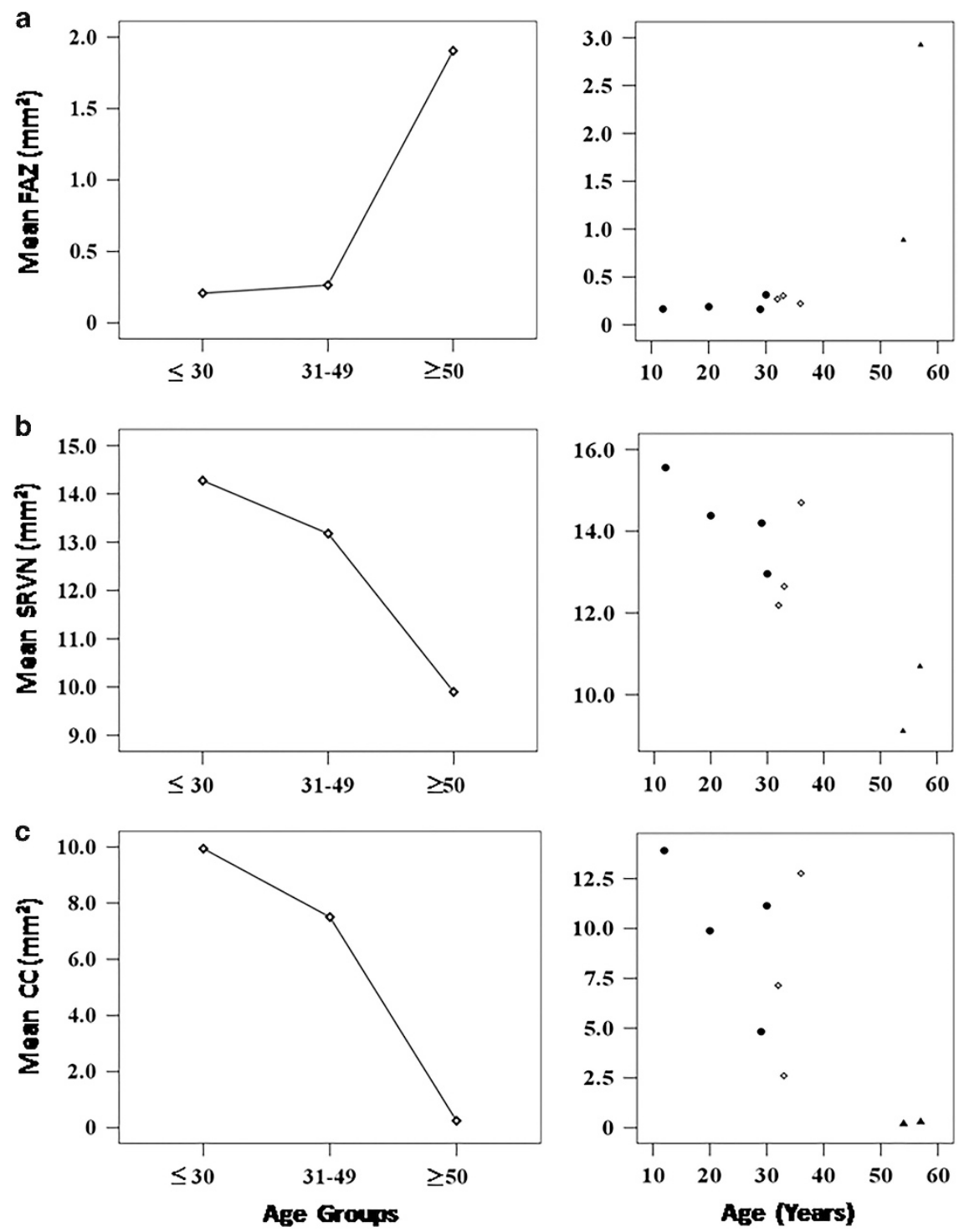

Figure 2 Scatter diagrams with trend line showing the mean value in $\mathrm{mm}^{2}$ of the (a) foveal avascular zone (FAZ); (b) superficial retinal vessel network (SRVN); and (c) choriocapillaris (CC) area with flow in CHM affected males within age subgroups: $(\bullet) \leqslant 30$ years; $(\diamond)$ between 31 and 49 years old, and $(\mathbf{\Lambda}) \geqslant 50$ years.

molecules, for example, soluble vascular endothelial growth factor (VEGF) isoforms released from the basolateral membrane maintain the vitality of the CC and the integrity of the CC fenestrations that disappear with VEGF depletion and lead to atrophy. ${ }^{26,28-30}$ We can assume that the reduction in the secretion of VEGF following RPE disruption can lead to a progressive CC atrophy that increases the instability of the RPE. The main function of the CC is to deliver oxygen and remove metabolites from the RPE and the outer retina that has the highest metabolic demand of all biological tissues. ${ }^{31}$ The $\mathrm{CC}$ is the only route for metabolic exchange in the retina within the FAZ. We identified a negative correlation between the CC area with flow and the FAZ area. This means that the reduction in the CC area with flow may be associated with an enlargement of the FAZ that may be related to a reduction in the visual acuity outcome. The identification of flow area change in subjects with $\mathrm{CHM}$ may be important for management and therapeutic end points.

Interestingly, the RPE has been found to regenerate together with CC in some animal models, such as in the rabbit following iodate-induced retinopathy. ${ }^{32-34}$ Majji and colleagues ${ }^{32,34}$ developed a surgical model of CC atrophy by surgically debriding the RPE in rabbits. The RPE regenerated in a centripetal manner, covering the 

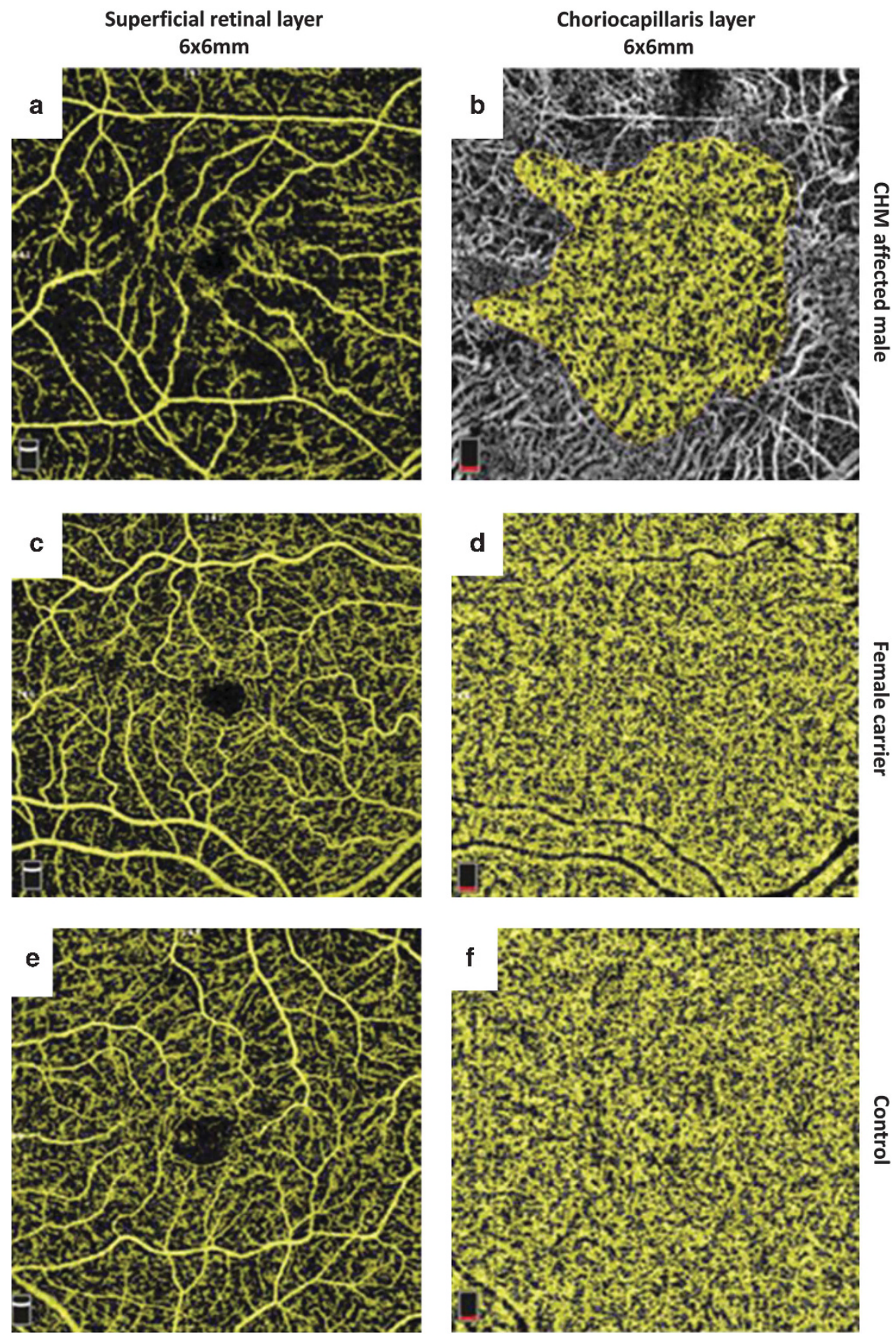

Figure 3 Optical coherence tomography angiography (OCTA) images of CHM affected male, female carrier, and control. Macular angiograms $6 \times 6$ shows $(a, c, e)$ superficial retinal layer and $(b, d, f) C C$ layer with automatic flow detection highlighted in yellow.

wounded area by day 7 post injury followed by CC revascularization by $4-8$ weeks. Using this model, the area of RPE cell loss can be controlled and the effects of pharmacological agents on CC can be measured. The identification of the molecular trigger could be beneficial for potential targeted regenerative treatment in human subjects and OCTA may be a good instrument to follow subjects during the regenerative phase.
In this study the SRVN was found to show a significantly lower area of capillary plexus with flow in affected males compared with female carriers and controls, suggesting that ischaemic conditions affect the outer retinal layers. This parameter was associated with an enlargement of FAZ, but did not reach statistical significance among the different groups. Abnormalities in the superficial capillary plexus were reported in a recent 
paper that analysed Stargardt's disease by OCTA ${ }^{35}$ but this feature was expected as the disease affects the central retina. It remains unclear why we observe superficial retinal vascular changes in $\mathrm{CHM}$ when the central retina tissue is still preserved. It may be related to the reduction in the CC area with flow, influencing a reduction in the superficial retinal circulation to maintain a balance between both circulatory networks. Interestingly, in high myopia a correlation exists between decreased choroidal blood flow and reduction of the SVRN. ${ }^{36,37}$ Decreased choroidal blood flow is considered the outcome of increased axial length resulting in ocular elongation stretching the vessels and modifying the retinal microvascular network. ${ }^{36}$

In $\mathrm{CHM}$ patients, the progressive atrophy of the $\mathrm{CC}$ and choroid may directly affect the outer retinal supply and also the retinal vasculature system.

Vascularity of the retina is not related to the volume of tissue but to metabolic need, ${ }^{38}$ and hence reduction in photoreceptor density and subsequent ganglion cells can be the cause of constriction of capillary network. A different assumption can be based on the reduced levels of VEGF secretion from the RPE. The lack of VEGF can downregulate both the growth of the retinal capillary network and the $\mathrm{CC}$ vessels. In subjects with diabetes, a reduction of the superficial capillary network has been reported ${ }^{39}$ and it was associated with a decrement of contrast sensitivity and visual field defects. ${ }^{40,41}$ We can assume that changes in the capillary network may play a role in CHM subjects causing similar loss of function. Moreover, a reduction of blue colour discrimination among patients with CHM have been noted in line with the loss of photoreceptors in the peripheral retina area (Mariya Moosajee, personal communication) where the short wave cones are more highly represented. ${ }^{42}$ Similar colour vision impairment is reported in type II diabetic patients preceding vascular alterations in the peripheral retina. ${ }^{43}$

Studying changes over time between vascularization and functional tests may provide useful data for these subjects. The relationship between age and CC area with flow was previously described by Mullins et a ${ }^{44}$ who reported increased choroidal non-perfusion with age. In affected male CHM patients, we found that the age is an important factor for the reduction of the CC area perfused. No statistical difference in mean FAZ, SRVN, and CC area of flow was found with any age group, but this is likely because of the small sample size. However, affected male CHM patients show a trend toward a reduction in CC and SRVN, and increase in FAZ with increasing age. This result is in line with the evolution of the disease and its progression over the time.
Our analysis presents some limitations, including its small sample size for each category because of the rare disease status of CHM. There is a lack of standardization of OCTA analysis protocol, highlighted by no previous studies using OCTA to analyse the difference in CC between male CHM patients, female carriers, and normal controls. This is a prospective observational study that allows us to report these features; however, further larger studies are required, in addition to natural history studies from a young age to monitor the changes in the $\mathrm{CC}$ over time. The manual selection of the CC layer was fundamental to select the correct layer and to analyse the area with flow area avoiding the inclusion of deep choroidal vessels. The automatic segmentation was not reliable in affected males compared with female carriers and controls, as it often included different layers. Furthermore, we excluded subjects with poor fixation leading to the exclusion of more advanced stages of the disease. OCTA is able to detect normal capillary flow between 0.4 and $3 \mathrm{~mm} / \mathrm{s},{ }^{45,46}$ and this value includes the CC blood velocity that is estimated to be $\sim 0.48$ to $2.45 \mathrm{~mm} / \mathrm{s}^{47-49}$ but it may be limited by areas where blood flow is $<0.4 \mathrm{~mm} / \mathrm{s},{ }^{45,46}$ and where shadowing from overlying retinal vessels cause an overrepresentation of areas without perfusion. In addition, the data reported on the SRVN included both small vessels and the capillary network. The software provided does not allow differentiation between these two systems. A $6 \times 6 \mathrm{~mm}$ analysis was preferred to the $3 \times 3 \mathrm{~mm}$ analysis because the quality of the images showed less artefacts especially for patients with difficulty in maintaining fixation and it allows us to image outside of the central retinal islands where the CC is atrophied and corresponding SRVN is reduced.

In conclusion, OCTA provides an estimation of the CC blood status even if it remains challenging. It shows blood flow impairment in both superficial and CC layers in $\mathrm{CHM}$ subjects. It does play an important role for better understanding the pathogenesis of choroideremia, allowing the application for new therapeutic strategies and monitoring of disease progression.

\section{Summary}

What was known before

- It is established that choroideremia induces changes in choroidal circulation and in the outer retinal layer in affected male subjects.

What this study adds

- This is the first study to identify reduced area with flow in the superficial retinal vessel network in the peripheral area of the retina where the choriocapillaris is fully atrophied. OCTA may be a useful tool for monitoring natural history and disease progression in forthcoming clinical trials. 


\section{Conflict of interest}

The authors declare no conflict of interest.

\section{Acknowledgements}

We gratefully acknowledge the support of the National Institute for Health Research (NIHR) Biomedical Research Centre based at Moorfields Eye Hospital NHS Foundation Trust and UCL Institute of Ophthalmology and the Choroideremia Research Foundation, Inc., USA.

\section{References}

1 Mauthner H. Ein fall von choroideremia. Ber Naturw Med Ver Innsbruck 1872; 2: 191.

2 van den Hurk JA, Schwartz M, van Bokhoven $H$, van de Pol TJ, Bogerd L, Pinckers AJ et al. Molecular basis of choroideremia (CHM): mutations involving the Rab escort protein-1 (REP-1) gene. Hum Mutat 1997; 9(2): 110-117.

3 MacDonald IM, Hume S, Chan S, Seabra MC. Choroideremia. In: Pagon RA, Adam MP, Ardinger HH et al (eds). GeneReviews(R): Seattle (WA), 1993-2017.

4 Moosajee M, Ramsden SC, Black GC, Seabra MC, Webster AR. Clinical utility gene card for: choroideremia. Eur J Hum Genet 2014; 22(4). doi: 10.1038/ejhg.2013.183.

5 Hayreh SS. The choriocapillaris. Albrecht Von Graefes Archr Klin Exp Ophthalmol 1974; 192(3): 165-179.

6 Torczynski E, Tso MO. The architecture of the choriocapillaris at the posterior pole. Am J Ophthalmol 1976; 81(4): 428-440.

7 Morgan JI, Han G, Klinman E, Maguire WM, Chung DC, Maguire AM et al. High-resolution adaptive optics retinal imaging of cellular structure in choroideremia. Invest Ophthalmol Vis Sci 2014; 55(10): 6381-6397.

8 Huang D, Swanson EA, Lin CP, Schuman JS, Stinson WG, Chang W et al. Optical coherence tomography. Science 1991; 254(5035): 1178-1181.

9 Puliafito CA, Hee MR, Lin CP, Reichel E, Schuman JS, Duker JS et al. Imaging of macular diseases with optical coherence tomography. Ophthalmology 1995; 102(2): 217-229.

10 Cameron JD, Fine BS, Shapiro I. Histopathologic observations in choroideremia with emphasis on vascular changes of the uveal tract. Ophthalmology 1987; 94(2): 187-196.

11 Flannery JG, Bird AC, Farber DB, Weleber RG, Bok D. A histopathologic study of a choroideremia carrier. Invest Ophthalmol Vis Sci 1990; 31(2): 229-236.

12 Anand-Apte B, Hollyfield J. Developmental anatomy of the retinal and choroidal vasculature. In: Besharse J, Bok D (eds). The Retina and Its Disorders. Elsevier: The Netherlands; 2010 pp 179-186.

13 Jia Y, Tan O, Tokayer J, Potsaid B, Wang Y, Liu JJ et al. Splitspectrum amplitude-decorrelation angiography with optical coherence tomography. Opt Exp 2012; 20(4): 4710-4725.

14 Jia Y, Bailey ST, Hwang TS, McClintic SM, Gao SS, Pennesi ME et al. Quantitative optical coherence tomography angiography of vascular abnormalities in the living human eye. Proc Natl Acad Sci USA 2015; 112(18): E2395-E2402.

15 Gao SS, Liu G, Huang D, Jia Y. Optimization of the splitspectrum amplitude-decorrelation angiography algorithm on a spectral optical coherence tomography system. Opt Lett 2015; 40(10): 2305-2308.

16 Alten F, Heiduschka P, Clemens CR, Eter N. Exploring choriocapillaris under reticular pseudodrusen using OCTAngiography. Graefes Arch Clin Exp Ophthalmol 2016; 254: 2165-2173.

17 Wang Q, Chan S, Yang JY, You B, Wang YX, Jonas JB et al. Vascular density in retina and choriocapillaris as measured by optical coherence tomography angiography. Am J Ophthalmol 2016; 168: 95-109.

18 Choi W, Mohler KJ, Potsaid B, Lu CD, Liu JJ, Jayaraman V et al. Choriocapillaris and choroidal microvasculature imaging with ultrahigh speed OCT angiography. PLoS One 2013; 8(12): e81499.

19 Ferrara D, Waheed NK, Duker JS. Investigating the choriocapillaris and choroidal vasculature with new optical coherence tomography technologies. Prog Retin Eye Res 2016; 52: 130-155.

20 Karakosta A, Vassilaki M, Plainis S, Elfadl NH, Tsilimbaris M, Moschandreas J. Choice of analytic approach for eye-specific outcomes: one eye or two? Am J Ophthalmol 2012; 153(3): 571-579 e571.

21 Murdoch IE, Morris SS, Cousens SN. People and eyes: statistical approaches in ophthalmology. Br J Ophthalmol 1998; 82(8): 971-973.

22 Spaide RF. Choriocapillaris flow features follow a power law distribution: implications for characterization and mechanisms of disease progression. Am J Ophthalmol 2016; 170: 58-67.

23 Sarks JP, Sarks SH, Killingsworth MC. Evolution of geographic atrophy of the retinal pigment epithelium. Eye (Lond) 1988; 2(Pt 5): 552-577.

24 Korte GE, Pua F. Choriocapillaris regeneration in the rabbit: a study with vascular casts. Acta Anat 1988; 133(3): 224-228.

25 Jain N, Jia Y, Gao SS, Zhang X, Weleber RG, Huang D et al. Optical coherence tomography angiography in choroideremia: correlating choriocapillaris loss with overlying degeneration. JAMA Ophthalmol 2016; 134(6): 697-702.

26 Henkind P, Gartner S. The relationship between retinal pigment epithelium and the choriocapillaris. Trans Ophthalmol Soc UK 1983; 103(Pt 4): 444-447.

27 Mancini MA, Frank RN, Keirn RJ, Kennedy A, Khoury JK. Does the retinal pigment epithelium polarize the choriocapillaris? Invest Ophthalmol Vis Sci 1986; 27(3): 336-345.

28 Kay P, Yang YC, Paraoan L. Directional protein secretion by the retinal pigment epithelium: roles in retinal health and the development of age-related macular degeneration. J Cell Mol Med 2013; 17(7): 833-843.

29 Mrejen S, Spaide RF. Optical coherence tomography: imaging of the choroid and beyond. Surv Ophthalmol 2013; 58(5): 387-429.

30 Saint-Geniez M, Kurihara T, Sekiyama E, Maldonado AE, D'Amore PA. An essential role for RPE-derived soluble VEGF in the maintenance of the choriocapillaris. Proc Natl Acad Sci USA 2009; 106(44): 18751-18756.

31 Wangsa-Wirawan ND, Linsenmeier RA. Retinal oxygen: fundamental and clinical aspects. Arch Ophthalmol 2003; 121(4): 547-557.

32 Hayashi A, Majji AB, Fujioka S, Kim HC, Fukushima I, de Juan E Jr. Surgically induced degeneration and regeneration of the choriocapillaris in rabbit. Graefes Arch Clin Exp Ophthalmol 1999; 237(8): 668-677. 
33 Korte GE, Reppucci V, Henkind P. RPE destruction causes choriocapillary atrophy. Invest Ophthalmol Vis Sci 1984; 25(10): 1135-1145.

34 Majji AB, de Juan E Jr. Retinal pigment epithelial autotransplantation: morphological changes in retina and choroid. Graefes Arch Clin Exp Ophthalmol 2000; 238(9): 779-791.

35 Battaglia Parodi M, Cicinelli MV, Rabiolo A, Pierro L, Bolognesi G, Bandello F. Vascular abnormalities in patients with Stargardt disease assessed with optical coherence tomography angiography. Br J Ophthalmol 2017; 101: 780-785.

36 Li M, Yang Y, Jiang H, Gregori G, Roisman L, Zheng F et al. Retinal microvascular network and microcirculation assessments in high myopia. Am J Ophthalmol 2017; 174: 56-67.

37 Meng W, Butterworth J, Malecaze F, Calvas P. Axial length of myopia: a review of current research. Ophthalmologica 2011; 225(3): 127-134.

38 Snodderly DM, Weinhaus RS, Choi JC. Neural-vascular relationships in central retina of macaque monkeys (Macaca fascicularis). J Neurosci 1992; 12(4): 1169-1193.

39 Byeon SH, Chu YK, Lee H, Lee SY, Kwon OW. Foveal ganglion cell layer damage in ischemic diabetic maculopathy: correlation of optical coherence tomographic and anatomic changes. Ophthalmology 2009; 116(10): 1949-1959.

40 Arend O, Remky A, Evans D, Stuber R, Harris A. Contrast sensitivity loss is coupled with capillary dropout in patients with diabetes. Invest Ophthalmol Vis Sci 1997; 38(9): 1819-1824.

41 Unoki N, Nishijima K, Sakamoto A, Kita M, Watanabe D, Hangai $\mathrm{M}$ et al. Retinal sensitivity loss and structural disturbance in areas of capillary nonperfusion of eyes with diabetic retinopathy. Am J Ophthalmol 2007; 144(5): 755-760.

42 Mullen KT, Kingdom FA. Differential distributions of redgreen and blue-yellow cone opponency across the visual field. Vis Neurosci 2002; 19(1): 109-118.

43 Feitosa-Santana C, Paramei GV, Nishi M, Gualtieri M, Costa MF, Ventura DF. Color vision impairment in type 2 diabetes assessed by the D-15d test and the Cambridge Colour Test. Ophthalmic Physiol Opt 2010; 30(5): 717-723.

44 Mullins RF, Johnson MN, Faidley EA, Skeie JM, Huang J. Choriocapillaris vascular dropout related to density of drusen in human eyes with early age-related macular degeneration. Invest Ophthalmol Vis Sci 2011; 52(3): $1606-1612$.

45 Tokayer J, Jia Y, Dhalla AH, Huang D. Blood flow velocity quantification using split-spectrum amplitude-decorrelation angiography with optical coherence tomography. Biomed Opt Expres 2013; 4(10): 1909-1924.

46 Tam J, Tiruveedhula P, Roorda A. Characterization of singlefile flow through human retinal parafoveal capillaries using an adaptive optics scanning laser ophthalmoscope. Biomed Opt Expres 2011; 2(4): 781-793.

47 Takasu I, Shiraga F, Okanouchi T, Tsuchida Y, Ohtsuki H. Evaluation of leukocyte dynamics in choroidal circulation with indocyanine green-stained leukocytes. Invest Ophthalmol Vis Sci 2000; 41(10): 2844-2848.

48 Zhu L, Zheng Y, von Kerczek CH, Topoleski LD, Flower RW. Feasibility of extracting velocity distribution in choriocapillaris in human eyes from ICG dye angiograms. J Biomech Eng 2006; 128(2): 203-209.

49 Flower RW, Fryczkowski AW, McLeod DS. Variability in choriocapillaris blood flow distribution. Invest Ophthalmol Vis Sci 1995; 36(7): 1247-1258.

Supplementary Information accompanies this paper on Eye website (http://www.nature.com/eye) 